\title{
Desempenho de morangueiro frente a diferentes espectros de radiação artificial complementar em cultivo sem solo
}

\author{
Performance of strawberry plants against different spectra of complementary artificial radiation in \\ cultivation without soil
}

\section{José Tobias Marks Machado ${ }^{1 *}$, Jeferson Tonin ${ }^{2}$, Lisiane Sobucki ${ }^{3}$, Bruna Rohrig ${ }^{4}$, Gerson Vignolo ${ }^{4}$, Débora Leitzke Betemps ${ }^{5}$ \& Evandro Pedro Schneider ${ }^{5}$}

\author{
${ }^{1}$ Universidade Federal do Rio Grande do Sul, Porto Alegre, RS, Brasil. *Autor para correspondência: tobias.machado@hotmail.com. \\ ${ }^{2}$ Instituto Federal Farroupilha, Frederico Westphalen, RS, Brasil. \\ ${ }^{3}$ Universidade Federal de Santa Maria, Santa Maria, RS, Brasil. \\ ${ }^{4}$ Universidade Federal de Pelotas, Pelotas, RS, Brasil. \\ ${ }^{5}$ Universidade Federal da Fronteira Sul, Cerro Largo, RS, Brasil.
}

Submissão: 30/03/2017 / Aceite: 13/06/2018

\begin{abstract}
RESUMO
Dentre os vários insumos utilizados no cultivo do morangueiro, a radiação artificial complementar tem sido ferramenta utilizada em cultivos de alto valor agregado em diversos países do exterior. O objetivo desse trabalho foi avaliar os efeitos agronômicos da complementação com radiação fotossinteticamente ativa em diferentes espectros na cultura do morangueiro, via utilização de lâmpadas fluorescentes em cultivo protegido e sem solo. Utilizou-se delineamento inteiramente casualizado com quatro repetições. A emissão de radiação em diferentes faixas espectrais compuseram os tratamentos, sendo utilizadas para isso lâmpadas fluorescentes de cor branca, azul, vermelha, a combinação de lâmpadas azuis e vermelhas, e a testemunha sem radiação complementar. Foram avaliados aspectos fisiológicos, fenológicos e produtivos. O uso de lâmpadas azuis e vermelhas de forma combinada, e o uso de lâmpadas brancas, anteciparam a floração e aumentaram a massa de frutas produzidas ao longo do ciclo produtivo do morangueiro. A luz azul induziu a produção de frutas com maior massa média. Já a luz vermelha não teve efeitos sobre o aumento da produção nem sobre o adiantamento da floração.
\end{abstract}

PALAVRAS-CHAVE: Fragaria x ananassa, clorofila, área foliar, precocidade, produção.

\begin{abstract}
Among the various inputs used in strawberry cultivation, complementary artificial radiation has been a tool used in crops of high added-value. The this study was to evaluate the agronomic effects of complementation with photosynthetically active radiation in different spectra on strawberry crops, using fluorescent lamps in protected cultivation without soil. A completely randomized design with four replicates was used. The treatments encompassed the emission of radiation in different spectral ranges, using white, blue and red fluorescent lamps, and the combination of blue and red lamps. There was a control group without complementary radiation. Physiological, phenological and production aspects were evaluated. The use of combined blue and red lamps, and of white lamps, anticipated flowering and increased the mass of fruit produced over the crop cycle. Blue lamps induced the production of fruits with great mean mass. Red lamps had no effects on the increase in production nor on the anticipation of flowering.
\end{abstract}

KEYWORDS: Fragaria x ananassa, chlorophyll, leaf area, precocity, production.

\section{INTRODUÇÃO}

O morangueiro (Fragaria $x$ ananassa Duch.) é uma das espécies de maior expressão econômica dentro do grupo das pequenas frutas, com produção estimada em 110 mil toneladas em uma área de 4.200 hectares (ANTUNES \& PERES 2013). A alta rentabilidade da produção justifica o grande interesse dos produtores na cultura (MADAIL et al. 2007), porém a susceptibilidade da planta ao ataque por patógenos de solo tem feito com que o cultivo convencional tenha enfrentado sérios problemas sanitários (CALVETE et al. 2007). O cultivo sem solo, em ambiente protegido, tem se mostrado viável na superação desses problemas, sendo apontadas como suas principais vantagens: a proteção da cultura contra ventos, granizos, baixas 
temperaturas, a minimização do ataque por pragas e doenças, e o aumento da produtividade (ANTUNES et al. 2007, GIMÉNEZ et al. 2008).

Tratando-se em específico do aumento da produção, o cultivo em ambiente protegido permite a simulação de condições ideais para o crescimento e desenvolvimento do morangueiro (CALVETE et. al. 2012). Nesse sentido, em cultivos de alto valor agregado, como o caso dessa cultura, o uso de radiação artificial complementar tem sido utilizado como ferramenta potencial para o aumento da produção, aumento da qualidade das frutas, ou ainda, na indução do florescimento, sendo, por isso, objeto de diversos estudos em países do exterior (OUZOUNIS et al. 2015).

O uso de radiação artificial em cultivos agrícolas parte do pressuposto básico de que os diferentes espectros da radiação fotossinteticamente ativa estimulam respostas diferenciadas nas plantas. Nesse sentido, a transferência de radiação no espectro do azul $(440$ - $490 \mathrm{~nm}$ ) intensifica o fototropismo (TAIZ \& ZEIGER 2013). COSTA (2011), destaca que a luz azul também pode aumentar a fotossíntese em morangueiro. Em estudo pioneiro, com mesma cultura, KIRSCHBAUM (1998) analisou os efeitos da radiação fotossinteticamente ativa nos espectros do vermelho e vermelho distante (600 - $710 \mathrm{~nm})$, concluindo que baixas intensidades induzem o florescimento sob fotoperíodo curto em cultivos protegidos. Dessa forma, a produção de flores e frutas poderia ser antecipada com o uso de radiação complementar que emitam comprimento de onda na faixa do vermelho $(600 \mathrm{~nm})$ e de intensidades nos níveis de 100 a 150 $\mu \mathrm{mol} \mathrm{m} \mathrm{m}^{-2} \mathrm{~s}^{-1}$. Em termos agronômicos, COCCO et al. (2011) destacam que a possibilidade de adiantamento na produção de morangos tem garantido ao produtor, maior rentabilidade do cultivo em várias regiões.

No Brasil a literatura a respeito da utilização radiação artificial complementar em cultivos comerciais é escassa, ainda que na propagação de plantas seja prática já conhecida e comumente utilizada (ROCHA et al. 2010). Diante disso, o objetivo desse trabalho foi avaliar os efeitos agronômicos da complementação com radiação fotossinteticamente ativa em diferentes espectros na cultura do morangueiro, via utilização de lâmpadas fluorescentes em cultivo sem solo. Em termos mais específicos, o trabalho pretende analisar os efeitos do uso da radiação complementar sobre os aspectos fisiológicos, fenológicos e produtivos da cultura.

Cabe destacar que o trabalho tem um viés exploratório e um caráter inédito, uma vez que como afirmado não são encontrados trabalhos sobre o tema no Brasil. Além disso, a problemática de pesquisa da qual parte o trabalho se refere ao fato de que o conhecimento dos principais efeitos agronômicos do uso da radiação artificial poderá apontar o efeito ou não efeito do uso dessa técnica para aumento da produção e/ou antecipação da produção. Então, deve ser salientado que quando reconhecida a falta de informação sobre a temática, os resultados do presente trabalho poderão, ao menos, subsidiar o desenvolvimento de trabalhos posteriores sobre o assunto.

\section{MATERIAL E MÉTODOS}

A implantação do experimento foi realizada em área experimental pertencente à Universidade Federal da Fronteira Sul campus Cerro Largo, com altitude 230 metros e com localização geográfica de $28^{\circ} 08^{\prime}$ de latitude ao sul e $54^{\circ} 44^{\prime}$ de longitude a oeste. O experimento foi conduzido sobre bancadas protegidas por túnel baixo coberto por polietileno transparente com espessura de $150 \mu \mathrm{m}$ e construída em sentido nortesul. As mudas foram implantadas em sacolas de polietileno (slabs), de cor branca preenchidas com substrato.

Foram utilizadas mudas da cultivar Camarosa, as quais foram transplantadas no dia 02/06/2015 e padronizadas pelo tamanho da coroa, de modo que houvesse uma homogeneização da condição inicial das mudas em todos os tratamentos $A$ duração do experimento foi de um ciclo de cultivo. A condução do experimento foi em delineamento inteiramente casualizado com quatro repetições, sendo cada repetição composta por duas plantas. Cada tratamento foi acondicionado em uma sacola de polietileno, de modo que cada um dos slabs acomodou quatro repetições. Foram utilizados cinco tratamentos, sendo quatro fontes luminosas distintas pelas faixas espectrais de radiação emitida e uma testemunha, sem radiação artificial. As fontes luminosas utilizadas foram lâmpadas fluorescentes da marca Foxlux ${ }^{\circledR}$, sendo os tratamentos: lâmpadas de cor azul, vermelha e branca, com espectro de emissão aproximado de 450 nm, 650 nm e 450$650 \mathrm{~nm}$, respectivamente.

O tratamento 1 (branco), foi constituído por quatro lâmpadas brancas com potência nominal de 15 watts; o tratamento 2 (azul + vermelho) foi constituído por três lâmpadas azuis e três lâmpadas vermelhas, todas com potência nominal de 13 watts. O tratamento 3 (azul), foi constituído por quatro lâmpadas azuis com potência nominal de 13 watts. O tratamento 4 (vermelho) foi constituído por quatro lâmpadas vermelhas com potência nominal de 13 watts. $O$ tratamento 5 , não recebeu radiação artificial complementar, sendo considerada testemunha. Doravante, no texto e nas tabelas, os tratamentos serão chamados de 'branco', 
'azul + vermelho', 'azul', 'vermelho' e testemunha.

Todos os tratamentos em que houve utilização de radiação fotossinteticamente ativa complementar tiveram mesma intensidade de radiação emitida ao dossel de plantas, sendo esta de $100 \mu \mathrm{mol} \mathrm{m}^{-2} \mathrm{~s}^{-1}$. A medida da intensidade da radiação foi feita com a auxílio de luximetro (Sunche - Light meter HS1010), posicionado na altura central do dossel, sendo a medida expressa em 'lux' transformada para intensidade $\mathrm{em}$ ' $\mu \mathrm{mol} \mathrm{m} \mathrm{m}^{-2} \mathrm{~s}^{-1}$. Semanalmente se realizaram medições da intensidade emitida, e quando necessária à altura das lâmpadas foi alterada de forma a se obter a intensidade pré-estabelecida em todo ciclo de cultivo. É importante salientar que embora haja um número diferente de lâmpadas entre tratamentos, isso não influenciou o efeito dos mesmos, uma vez que a intensidade de radiação foi aferida de modo que houvesse igual intensidades em todos os tratamentos $\left(100 \mu \mathrm{mol} \mathrm{m}^{-2} \mathrm{~s}^{-1}\right)$, sendo que a diferença do número de lâmpadas existiu para que, justamente, todos recebessem luz em mesma intensidade.

O dossel recebeu radiação artificial de 5 horas diárias divididas em dois períodos do dia, o qual foi complementar no período da manhã, entre 6:00 e 9:00 (três horas de complementação), e das 16:00 às 18:00 (duas horas de complementação) ${ }^{1}$. Um temporizador analógico ligado à fonte de energia foi utilizado para o acionamento do sistema de complementação de radiação.

Como destacado incialmente, o trabalho buscou avaliar os efeitos dos tratamentos sobre aspectos fisiológicos, fenológicos e produtivos da cultura. Tratando-se dos aspectos fisiológicos foram realizadas avaliações para determinação dos teores de clorofila nas folhas. Tais avaliações tiveram como objetivo analisar o comportamento dessa variável em três momentos do ciclo vegetativo: no estabelecimento das plantas a campo, sendo considerado estabelecimento como o momento em que as plantas tivessem dois trifólios totalmente expandidos; no período intermediário entre o estabelecimento das plantas e o fim do período vegetativo; e ao final do período vegetativo. A determinação desses momentos de avaliação seguiram os seguintes parâmetros: A primeira avaliação foi feita quando a metade das repetições de todos os tratamentos apresentaram ao menos dois trifólios totalmente expandidos, fenômeno que ocorreu no $18^{\circ}$ dia após o transplantio (18 DAT). O cálculo para a realização da segunda avaliação levou em consideração a duração aproximada do ciclo vegetativo da cultivar, 50 DAT (DIAS et al. 2014). Sendo que a subtração da duração aproximada do período vegetativo (50 DAT) com a duração do período de estabelecimento (18 DAT) chegou-se a um valor $32 \mathrm{DAT}^{2}$, de modo que o período intermediário entre o período de estabelecimento seria de 16 dias após o estabelecimento ${ }^{3}$, devendo ser feita a avaliação no $34^{\circ}$ DAT $^{4}$. Por condições climáticas inviáveis para a coleta de amostras a campo, a segunda avaliação foi feita um dia posterior ao previsto (35 DAT). A última avaliação foi feita ao final do ciclo vegetativo, com início da floração, considerada quando metade das plantas de todos os tratamentos tivessem duas flores abertas, tal fenômeno ocorreu no $52^{\circ}$ DAT, momento em que foi efetuada a terceira e última determinação dos teores de clorofila.

Para determinação dos teores de clorofila, as folhas foram coletadas a campo e acondicionadas em papel alumínio sendo imediatamente armazenadas em caixa de isopor resfriada com gelo e encaminhadas ao laboratório. A extração seguiu o método descrito por TELLES et al. (1977), via espectrofotometria, sendo a determinação de clorofilas $a, b$ e total, feitas por equações propostas por ARNON (1949) e o resultado expresso em $\mu \mathrm{g}^{-1}$ de clorofila $\mathrm{g}^{-1}$ de folha $\left(\mu \mathrm{g}^{-1} \mathrm{~g}^{-1}\right)$.

Tratando-se dos aspectos fenológicos, ao final do ciclo vegetativo, foi feita a estimativa de área foliar dos tratamentos por método não destrutivo via medida do comprimento e largura dos folíolos e utilização de modelo linear proposto por PIRES et al. (1999) para cultura do morangueiro cultivada em ambiente protegido. Ainda tratando-se dos aspectos fenológicos, fez-se também a avaliação da capacidade de indução de floração dos tratamentos, sendo calculada a soma térmica acumulada do transplante até a floração plena e expressa em graus dia. Os dados utilizados foram provenientes da estação meteorológica automática do campus Cerro Largo da UFFS, sendo utilizada a temperatura base para soma térmica $7,3^{\circ} \mathrm{C}^{5}$ (CHAVARRIA \& SANTOS 2012).

Para os aspectos produtivos, fez-se a avaliação da produção em termos quantitativos e qualitativos. Sobre os aspectos quantitativos, as colheitas foram efetuadas da segunda quinzena de junho à primeira

\footnotetext{
${ }^{1}$ A escolha dos horários, matutino e vespertino se deu para que a radiação fosse complementar em horários de menor radiação natural, ou seja, no início da manhã e no final da tarde.

${ }^{2} 50 \mathrm{DAT}-18 \mathrm{DAT}=32 \mathrm{DAT}$

32 DAT $/ 2=16$ DAT

${ }^{4} 18 \mathrm{DAT}+16 \mathrm{DAT}=34 \mathrm{DAT}$

${ }^{5} \sum_{\mathrm{i}} \mathrm{T} \geq \mathrm{Tb} \quad$ em que:

$i=$ periodo entre o transplante e o início da floração / $T=$ Temperatura média de uma hora / Tb=7,3
}

Rev. Ciênc. Agrovet., Lages, SC, Brasil (ISSN 2238-1171) 
quinzena de dezembro, avaliando-se o número, massa de frutas por planta e a massa média das frutas obtida pela divisão da massa pelo número de frutas produzidas. Para os aspectos qualitativos da fruta, foram analisados o teor de sólidos solúveis, através de leitura direta em refratômetro digital sendo o resultado expresso em graus Brix; a acidez titulável determinada pelo método titulométrico; e a relação sólidos solúveis/acidez titulável, obtida pela razão destas duas variáveis.

Os dados coletados foram submetidos à análise de variância pelo teste $F$, sendo que quando significativas $(P \geq 0,05)$ tiveram as médias comparadas pelo teste de Scott-Knott a $5 \%$ de probabilidade de erro, por meio do programa estatístico Assistat. Todos os dados que se referiram a algum tipo de contagem (número de frutas, soma térmica, DAT), sofreram transformação quadrática para estabilização da variância.

\section{RESULTADOS E DISCUSSÃO}

Tratando-se do efeito da complementação de radiação sobre os aspectos fisiológicos do morangueiro, foram observadas diferenças sobre os teores de clorofila a e total ao longo do ciclo vegetativo, como pode ser observado na Tabela 1. Para os teores de clorofila $b$ não houve significância estatística dos dados em nenhuma das três avaliações. Na primeira avaliação, para clorofila a, os tratamentos 'branco', 'azul + vermelho' e 'azul' se destacaram estatisticamente sobre 'vermelho' e a 'testemunha'. Resultado esse o qual se repetiu para clorofila total nessa avaliação.

Tabela 1. Teores médios de clorofila $a$, clorofila $b$ e clorofila total em três momentos do ciclo vegetativo (18 DAT, 35 DAT, 51 DAT), expressos em $\mu \mathrm{g}^{-1}$ de clorofila por $\mathrm{g}^{-1}$ de folha de morangueiro.

Table 1. Mean values of chlorophyll a, chlorophyll $b$ and total chlorophyll at three times in the vegetative cycle (18 DAT, $35 \mathrm{DAT}, 51)$ expressed as $\mu \mathrm{g}^{-1}$ of chlorophyll per $\mathrm{g}^{-1}$ of strawberry leaf.

\begin{tabular}{|c|c|c|c|}
\hline \multirow{2}{*}{ Tratamento } & \multicolumn{3}{|c|}{$1^{a}$ Avaliação - $18 \operatorname{DAT}^{1}\left(\mu \mathrm{g}^{-1} \mathrm{~g}^{-1}\right)$} \\
\hline & Clorofila a & Clorofila $b$ & Clorofila total \\
\hline Branco & $1529,88 a$ & $500,27^{\text {ns }}$ & $2029,66 a$ \\
\hline Azul + vermelho & $1536,28 a$ & 495,71 & $2031,52 a$ \\
\hline Azul & $1461,82 a$ & 495,28 & $1956,63 a$ \\
\hline Vermelho & $1374,60 \mathrm{~b}$ & 458,53 & $1832,69 b$ \\
\hline Testemunha & $1342,52 \mathrm{~b}$ & 450,64 & $1792,73 \mathrm{~b}$ \\
\hline $\mathrm{CV}(\%)$ & 7,38 & 10,72 & 7,85 \\
\hline \multirow{2}{*}{ Tratamento } & \multicolumn{3}{|c|}{$2^{\mathrm{a}}$ Avaliação - 35 DAT $\left(\mu \mathrm{g}^{-1} \mathrm{~g}^{-1}\right)$} \\
\hline & Clorofila $a$ & Clorofila $b$ & Clorofila total \\
\hline Branco & $1716,90 \mathrm{~b}$ & 680,38 & $2396,68^{\text {ns }}$ \\
\hline Azul + vermelho & $1815,79 b$ & 717,70 & 2532,85 \\
\hline Azul & $1805,39 b$ & 736,03 & 2540,78 \\
\hline Vermelho & $1971,90 a$ & 705,74 & 2677,09 \\
\hline Testemunha & $1709,35 b$ & 642,93 & 2352,70 \\
\hline $\mathrm{CV}(\%)$ & 8,03 & 20,20 & 9,03 \\
\hline \multirow{2}{*}{ Tratamento } & \multicolumn{3}{|c|}{ 3a Avaliação - 51 DAT $\left(\mu \mathrm{g}^{-1} \mathrm{~g}^{-1}\right)$} \\
\hline & Clorofila a & Clorofila $b$ & Clorofila total \\
\hline Branco & $1911,58 b$ & 876,29 & $2787,15 b$ \\
\hline Azul + vermelho & $2004,45 a$ & 835,49 & $2839,23 b$ \\
\hline Azul & $1855,19 b$ & 774,59 & $2629,12 b$ \\
\hline Vermelho & $2145,14 a$ & 961,84 & $3106,18 a$ \\
\hline Testemunha & $1853,90 \mathrm{~b}$ & 784,40 & $2637,63 \mathrm{~b}$ \\
\hline CV (\%) & 7,63 & 17,65 & 9,83 \\
\hline
\end{tabular}


Aos 35 DAT houve inversão dos valores observados para os teores de clorofila $a$, havendo superioridade estatística do tratamento 'vermelho' sobre os demais. Para os teores clorofila total, não foi constatada significância estatística. Na última avaliação, ao final do ciclo vegetativo (51 DAT), os tratamentos 'vermelho' e 'azul + vermelho' se destacaram dos demais para a clorofila a. Para clorofila total na última avaliação, o tratamento com 'vermelho' é que se diferenciou, com um acúmulo de $3106,18 \mu^{-1} \mathrm{~g}^{-1}$.

Levando em consideração que a clorofila a é o pigmento mais ativo nas reações da fotossíntese, uma vez que clorofila $b$ é considerada como um pigmento acessório (TAIZ \& ZEIGER 2013), a análise conjunta das três avaliações permite inferir que o tratamento 'vermelho' seguido do tratamento 'azul + vermelho' obtiveram maior acúmulo de clorofila durante o período vegetativo.

A dinâmica de acúmulo de clorofila a e total, para o tratamento utilizando lâmpadas fluorescentes vermelhas, indicam que durante a primeira avaliação houve um menor acúmulo de clorofilas, havendo uma inversão deste comportamento nas seguintes avaliações. Isto pode estar relacionado às características fisiológicas do pigmento sensível à radiação vermelha, o fitocromo. Segundo TAIZ \& ZEIGER (2013), os efeitos da utilização de intensidades altas de radiação no espectro do vermelho durante um período prolongado, como o caso da utilização artificial complementar em $100 \mu \mathrm{mol} \mathrm{m}^{-2} \mathrm{~s}^{-1}$, acarretam em respostas lentas das plantas, que são observadas em dias ou semanas após o estímulo. Podendo ser essa a explicação para o menor acúmulo desse tratamento na primeira avaliação. LEFSRUD et al. (2008), avaliado os efeitos da radiação artificial sobre a couve-flor, observaram maior acumulo de clorofila a nos tratamentos com emissão de luz no espectro do vermelho, corroborando com os dados expostos no presente estudo.

O desempenho inferior, a partir da segunda avaliação, do tratamento com fluorescente emitindo luz 'azul', para todos os pigmentos fotossintetizantes avaliados, pode estar relacionado a menor eficiência do comprimento de onda da faixa espectral do azul para fotossíntese. De acordo com HARBINSON \& ROSENQVIST (2003), para chegar ao centro de reação da fotossíntese há necessidade de transformação da radiação azul em comprimentos menores do espectro, fazendo com que haja dissipação da energia. Com isso parte da radiação azul emitida sobre as plantas é perdida em forma de calor durante a sua absorção.

Por outro lado, o maior acúmulo de clorofila, nas avaliações em que houve significância estatística, para o tratamento 'azul + vermelho' pode ser explicado pelo efeito benéfico do 'vermelho' nesse processo. Isso pode ser facilmente constado ao passo que, excetuando-se os teores de clorofila total na última avaliação e clorofila a na segunda avaliação, tal tratamento mostrou-se estatisticamente tão eficiente quanto o tratamento utilizando radiação com vermelho individualmente no acúmulo de clorofila.

O menor efeito da utilização de radiação complementar com fluorescente branca, para o acúmulo de clorofila, pode estar relacionado às características físicas desse tratamento. Diferente das demais, a luz branca emite comprimentos de onda em um amplo espectro do visível (400 nm a $700 \mathrm{~nm}$ ), desse modo, considerando que foram utilizadas intensidades iguais em todos os tratamentos, $100 \mu \mathrm{mol} \mathrm{m} \mathrm{m}^{-1}$, a intensidade de radiação vermelha e azul emitidos pela fluorescente branca são inferiores aos demais, que emitem radiação em faixas estreitas do espectro. A não significância dos dados para clorofila $b$, nas condições do experimento, pode estar relacionada ao fato de que uma maior proporção dos teores desse pigmento, deve-se a resposta fisiológica de folhas sombreadas, as quais recebem grandes quantidades de radiação difusa e de baixa intensidade luminosa (ENGEL \& POGGIANI 1991).

Feita essa primeira incursão dos efeitos do uso da radiação complementar sobre o acúmulo de clorofila nas folhas, bem como as prováveis explicações fisiológicas para os resultados aferidos, cabem ser melhor exploradas as possíveis consequências de tal aumento do teor destes pigmentos fotossintetizantes no desenvolvimento da cultura. Nesse sentido ao testar o efeito da radiação artificial nos comprimentos de onda do azul e do vermelho sobre o morangueiro, SAMUOLIENÉ et al. (2010) observaram maior acúmulo de clorofila a e total nos tratamentos utilizando apenas diodos emissores de radiação na faixa do vermelho, condizendo com os resultados destacados aqui. Porém o trabalho dos autores destaca uma correlação negativa entre o aumento dos teores de clorofila e a produção de frutas, em que o tratamento com uso de radiação no espectro do vermelho obteve tanto uma menor produção de frutas por planta como também frutas com massa média inferior aos demais tratamentos. Havendo assim, segundo os autores, uma relação inversa entre o aumento da clorofila e a produção de morangueiro. Porém os mesmos não destacam uma relação clara para tal efeito.

Deve ser ponderado que diversos trabalhos apresentam correlações positivas entre os teores de clorofila e produção de cultivos, de feijão (SORATTO et al. 2004), milho (ARGENTA et al. 2008) e batata (COELHO et al. 2010) por exemplo. Porém tais trabalhos utilizam métodos indiretos de determinação de clorofila, fazendo a associação entre a clorofila e teores de nitrogênio presentes na folha. Nesse sentido, 
tanto o presente trabalho como no caso destacado por SAMUOLIENÉ et al. (2010), o aumento dos teores de clorofila são decorrentes do uso de radiação artificial, de modo que tais aumentos não necessariamente devam ter efeitos positivos sobre a produção.

Em relação aos aspectos fenológicos, os diferentes comprimentos de radiação artificial complementar influenciaram no tamanho do período vegetativo. Em termos estatísticos os tratamentos 'azul + vermelho' e 'branco' se diferenciaram dos demais tratamentos, encurtando esse período ao induzir floração mais precocemente, tanto pelo método da soma térmica como pela contagem da duração do período vegetativo em dias após o transplantio (Tabela 2).

Tabela 2. Duração do ciclo vegetativo do transplantio até a floração plena, medido pela duração em graus dia, FP $\left({ }^{\circ} \mathrm{C}\right.$ dia), e dias do calendário civil, FP (dias). Desempenho das plantas ao final do ciclo

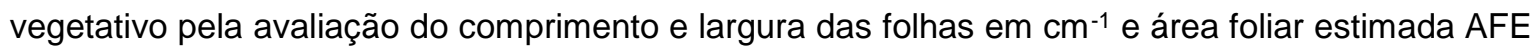
$\left(\mathrm{cm}^{-2}\right)$.

Table 2. Duration of vegetative cycle from transplanting to full flowering (FF), measured by duration in degrees day FF $\left({ }^{\circ} \mathrm{C}\right.$ day), and calendar days, FF (days). Plant performance at the end of the vegetative cycle by evaluation of leaf length and width in $\mathrm{cm}^{-1}$ and estimated leaf area $E L A\left(\mathrm{~cm}^{-2}\right)$.

\begin{tabular}{lccccc}
\hline Tratamento & FP & FP & & & \\
$\left({ }^{\circ} \mathrm{C}\right.$ dia $)$ & $($ Dias $)$ & Comprimento $\left(\mathrm{cm}^{-1}\right)$ & Largura $\left(\mathrm{cm}^{-1}\right)$ & AFE $\left(\mathrm{cm}^{-2}\right)$ \\
\hline Branco & $424,29 \mathrm{~b}$ & $47 \mathrm{~b}$ & $54,15 \mathrm{~b}$ & $50,03^{\text {ns }}$ & $169,32 \mathrm{~b}$ \\
Azul + vermelho & $408,68 \mathrm{~b}$ & $44 \mathrm{~b}$ & $100,01 \mathrm{a}$ & 77,53 & $301,72 \mathrm{a}$ \\
Azul & $464,87 \mathrm{a}$ & $51 \mathrm{a}$ & $60,28 \mathrm{~b}$ & 45,92 & $169,74 \mathrm{~b}$ \\
Vermelho & $466,65 \mathrm{a}$ & $50 \mathrm{a}$ & $64,55 \mathrm{~b}$ & 57,82 & $224,31 \mathrm{~b}$ \\
Testemunha & $467,99 \mathrm{a}$ & $52 \mathrm{a}$ & $52,77 \mathrm{~b}$ & 54,25 & $150,76 \mathrm{~b}$ \\
\hline CV $(\%)$ & 9,97 & 5,37 & 28,55 & 33,23 & 39,30 \\
\hline
\end{tabular}

Médias seguidas por mesma letra na coluna, não diferem entre si por teste de Scott-Knott a $5 \%$ de probabilidade de erro. ${ }^{\text {ns }}$ Dados sem significância estatística.

Além do aspecto estatístico, quando comparado a precocidade da floração do tratamento 'Azul + Vermelho' em relação a testemunha é notado que o uso de radiação adiantou a floração em oito dias, correspondendo a acúmulo térmico inferior em 59 graus dia. Por sua vez, a utilização de fluorescente branca adiantou a floração em cinco dias, comparativamente a testemunha. Já os tratamentos 'azul' e 'vermelho', não apresentaram efeitos sobre a indução de floração, não se diferenciando da testemunha, embora em termos numéricos tenham sido mais precoces que o tratamento sem nenhum tipo de complementação com luz. É importante destacar que o adiantamento da produção é um resultado buscado pelo produtor comercial de morangos (BECKER 2017), pelo fato de que a possibilidade de produção de morangos no período anterior ao pico produtivo, representa ganhos econômicos importantes, acarretando uma maior rentabilidade da produção comercial da fruta (TONIN et al. 2015, COCCO 2011).

Tratando das medidas de tamanho dos folíolos, ao final do ciclo produtivo, houve significância estatística para o comprimento das folhas e a para área foliar estimada, não havendo significância, em termos estatísticos, para a medida de largura dos folíolos (Tabela 2). Nesse sentido o tratamento 'azul + vermelho' se destacou sobre os demais tratamentos, tanto para o comprimento do folíolo como para a área foliar estimada. Estudando os efeitos agronômicos dos espectros de radiação vermelha em conjunto com o espectro de radiação azul, KIM et al. (2004), relataram efeito positivo desse tratamento no aumento da taxa fotossintética, a qual segundo ROSA et al. (2013) possui relação direta com área foliar das plantas. No entanto, segundo KIM et al. (2004), tal resposta na taxa não é ocorrente ao se utilizar azul e vermelho individualmente, corroborando ao apresentado aqui.

Segundo ZEIST et al. (2014) a área foliar é o principal parâmetro indicativo de produtividade da cultura do morangueiro. Na mesma linha ROSA et al. (2013) pontuam que o crescimento adequado das folhas resulta em um incremento na área foliar, o que permite aumento da interceptação de radiação solar, havendo por consequência a possibilidade de uma maior atividade fotossintética e maior produção da cultura, figurando, o aumento da área foliar como uma variável de interesse agronômico. Nesse sentido é interessante pontuar que, apesar de estatisticamente apenas o tratamento 'azul + vermelho' se sobressair, todos os tratamentos tiveram área foliar estimada superior à da testemunha.

A análise agregada dos dados fenológicos, permitem algumas inferências. A área foliar estimada 
superior aferida para o tratamento 'azul + vermelho', o qual pode ser analisado como um indicativo de uma maior taxa fotossintética (ROSA et al. 2013), pode ter relação direta com a capacidade de indução de floração desse tratamento. Por outro lado, o mesmo não é possível afirmar para o tratamento utilizando fluorescente branca, o qual em termos estatísticos também induziu precocidade de floração. De todo modo, de acordo com TAIZ \& ZEIGER (2013), níveis baixos de intensidade, bem como comprimentos de onda específicos é que são capazes de induzir respostas das plantas para a mudança de fase do período vegetativo ao reprodutivo. Assim, tal característica fisiológica em conjunto com a característica física da luz branca, de emitir todos os espectros do visível em intensidades baixas, podem ter relações com a precocidade induzida por esse tratamento.

O efeito não diferencial dos tratamentos 'azul' e 'vermelho', também podem se relacionar à menor área foliar de ambos tratamentos. Entretanto o retardamento da floração plena para o tratamento utilizando luz vermelha, condiz com os dados apontados por KIRSHBAUM (1998). De acordo com esse autor a emissão de luz no espectro do vermelho, sob fotoperíodo mais prolongado, pode levar a um retardamento da floração em cultivares de morangueiro de dias curtos, sendo que para esse autor, o espectro do vermelho tem efeito na indução de floração apenas quando o fotoperíodo não ultrapasse oito horas para os genótipos de dias curtos. Sendo assim, nas condições do experimento, a existência de um fotoperíodo superior a oito horas teve efeito de retardar a floração deste tratamento.

Quanto aos aspectos produtivos, em termos quantitativos, o tratamento 'azul + vermelho' se destacou sobre os demais, alcançando uma produção de 40 frutas por planta, ao longo do ciclo produtivo (Figura 1). A grande quantidade de frutas produzidas fez com que, mesmo tendo uma massa média de frutas baixa, apenas $10,71 \mathrm{~g}^{-1}$, tal tratamento se destacasse também quando tratado da massa de frutas produzidas. Para essa variável, os tratamentos 'branco' e 'azul' não se diferenciaram estatisticamente do tratamento 'azul + vermelho', embora em termos numéricos a superioridade foi do último.

O bom desempenho produtivo do tratamento 'azul + vermelho', pode ter relação direta com a área foliar estimada superior e com o acúmulo de clorofila na fase vegetativa. Para o cultivo em ambiente protegido SAMUOLIENE et al. (2010), confirmam ser a utilização em conjunto da radiação nos espectros do azul e do vermelho os mais eficientes para o crescimento, desenvolvimento e produção do morangueiro. Tratando-se novamente do tratamento 'branco', os aspectos fisiológicos e fenológicos não são capazes de explicar o bom desempenho produtivo desse tratamento. Porém cabe ser destacado que a luz branca é aquela que mais se aproxima das características da luz natural (OUZOUNIS et al. 2015) emitindo todos os espectros do visível. Nesse sentido, é possível que o aumento do fotoperíodo diário tenha incrementado a taxa fotossintética diária desse tratamento (TAIZ \& ZEIGER 2013), repercutindo por consequência sobre a massa de frutas produzidas. Sobre o tratamento utilizando luz 'azul' é plausível destacar, antes de tudo, que o mesmo, além de se destacar com a maior massa de frutas produzidas, se destacou individualmente na variável massa média das frutas. Produzindo frutas com massa média de $13,10 \mathrm{~g}^{-1}$, superior em $2,79 \mathrm{~g}^{-1}$ ao tratamento 'azul + vermelho', por exemplo. Desse modo, pode ser inferido que o destaque em termos produtivos alcançado por esse tratamento, se deu pela maior massa de suas frutas, podendo ser apontado, por consequência, a capacidade da luz azul em estimular a produção de frutas com maior tamanho. Embora não sejam encontrados trabalhos para a cultura do morangueiro, MÉNARD et al. (2006), observaram, na cultura do tomateiro, aumento da biomassa em conjunto com diminuição da produção de frutas ao utilizar LEDs nos espectros do azul (455 nm), de forma complementar, tal como aferido no presente trabalho. Nesse sentido o uso de luz azul pode figurar como uma estratégia para a produção de frutas maiores, sendo que de acordo com MACHADO et al. (2016), frutas com essa característica apresentam preferência pelo consumidor de morangos na forma in natura.

O baixo desempenho produtivo do tratamento 'vermelho' pode estar relacionado à combinação entre os efeitos do espectro do vermelho e a elevação do fotoperíodo acima de oito horas, sendo que como destacado anteriormente, para cultivares de dias curtos de morangueiro, fotoperíodos mais extensos inibem ou diminuem a floração. $O$ baixo desempenho produtivo desse tratamento, confirma também a relação inversa entre o aumento dos teores de clorofila e a produção de frutas, destacado por SAMUOLIENE et al. (2010).

Quanto às características qualitativas das frutas (Tabela 3), os valores para morangos maduros devem ser da ordem de 0,5 a 1,87 $\mathrm{g}^{-1}$ de ácido cítrico $100 \mathrm{~g}^{-1}$ polpa (KADER 1991). O tratamento azul + vermelho, se diferenciou dos demais tratamentos com a menor acidez titulável. Ainda são escassos os trabalhos referentes aos efeitos dos espectros de radiação fotossinteticamente ativa sobre a qualidade química dos frutos de morangueiro, sendo que OUZOUNIS et al. (2015), ao fazer uma revisão sobre os efeitos dos diferentes espectros sobre a fisiologia de plantas, não reporta trabalhos abordando tal assunto. 
Tabela 3. Produção de frutas morangueiro em número de frutas por planta-1 (NFP), massa das frutas planta (MFP), e massa média das frutas (MMF). Características químicas das frutas de morangueiro em sólidos solúveis SS ( ${ }^{\circ}$ Brix), acidez titulável (AT) (\% ácido cítrico) e relação entre sólidos solúveis e acidez titulável (SS/AT).

Table 3. Production of strawberry fruit in number of fruits per plant ${ }^{-1} N F P^{(1)}$, fruit mass per plant $F M P^{(2)}$, and mean mass of fruits $M M F^{(3)}$. Chemical characterization of strawberry fruits in soluble solids $S S$ $\left({ }^{\circ} \mathrm{Brix}\right)^{(4)}$, treatable acidity TA (\% citric acid) and soluble solids and treatable acidity ratio SS/TA(6).

\begin{tabular}{lcccccc}
\hline Tratamento & NFP & MFP & MMF & $\begin{array}{c}\text { SS } \\
\left({ }^{\circ} \text { Brix }\right)\end{array}$ & $\begin{array}{c}\text { AT } \\
\text { (\% ácido cítrico })\end{array}$ & SS/AT \\
\hline Branco & $35,33 \mathrm{~b}$ & $402,30 \mathrm{a}$ & $11,46 \mathrm{~b}$ & $6,88^{\text {ns }}$ & $1,40 \mathrm{a}$ & $4,89^{\text {ns }}$ \\
Azul + vermelho & $40,00 \mathrm{a}$ & $424,03 \mathrm{a}$ & $10,71 \mathrm{~b}$ & 5,43 & $1,11 \mathrm{~b}$ & 5,03 \\
Azul & $31,67 \mathrm{~b}$ & $405,50 \mathrm{a}$ & $13,10 \mathrm{a}$ & 5,46 & $1,28 \mathrm{a}$ & 4,27 \\
Vermelho & $34,33 \mathrm{~b}$ & $350,31 \mathrm{~b}$ & $10,38 \mathrm{~b}$ & 6,38 & $1,40 \mathrm{a}$ & 4,55 \\
Testemunha & $32,33 \mathrm{~b}$ & $373,34 \mathrm{~b}$ & $11,63 \mathrm{~b}$ & 5,68 & $1,33 \mathrm{a}$ & 4,33 \\
\hline CV (\%) & 13,12 & 10,51 & 16,49 & 19,07 & 12,78 & 20,02
\end{tabular}

Médias seguidas por mesma letra na coluna, não diferem entre si por teste de Scott-Knott a $5 \%$ de probabilidade de erro. ${ }^{\text {ns }}$ Dados sem significância estatística.

\section{CONCLUSÂO}

A pretensão inicial do trabalho foi avaliar e analisar os efeitos fisiológicos, fenológicos e produtivos do uso da radiação complementar na cultura do morangueiro. Nesse sentido, em termos fisiológicos o uso de fluorescentes vermelhas causam o aumento nos teores de clorofila na folha, no entanto há um efeito inverso entre o uso desse tratamento e a produção de frutas para a cultivar Camarosa.

Em relação a antecipação da produção, nas condições testadas, o uso da iluminação complementar, combinando lâmpadas azuis e vermelhas, induz floração antecipada, sendo que o mesmo acontece ao ser utilizada luz branca sobre o cultivo. Tratando-se dos efeitos produtivos, tanto o uso da combinação de lâmpadas azuis e vermelhas como o uso da luz branca aumentam a massa de frutas produzidas ao longo do ciclo. Assim esses dois tratamentos podem ser indicados para a antecipação e o aumento da massa de frutas produzidas. Ainda sobre aspectos produtivos, a luz azul induz aumento do tamanho das frutas, tendo por isso também efeitos positivos na produção ao longo do ciclo, podendo figurar como técnica para aumento do tamanho das frutas.

Por fim é cabível ser destacado que o trabalho cumpriu, tanto com a pretensão de apontar os efeitos do uso de radiação complementar sobre a produção de morangos, como também de gerar informações consistentes, mas não definitivas, a respeito do tema pesquisado.

\section{REFERÊNCIAS}

ANTUNES LEC \& PERES N. 2013. Strawberry Production in Brazil and South America. International Journal of Fruit Science 13: 156-161.

ANTUNES OT et al. 2007. Produção de cultivares de morangueiro polinizadas pela abelha jataí em ambiente protegido. Horticultura Brasileira 25: 94-99.

ARGENTA G et al. 2008. Adubação nitrogenada em milho pelo monitoramento do nível de nitrogênio na planta por meio do clorofilômetro. Revista Brasileira de Ciência do Solo 27: 109-119.

ARNON DI. 1949. Copper enzymes in isolated chloroplasts: polyphenoloxidases in Beta vulgaris. Plant Physiology 24: 115.

BECKER T. 2017. Produção de mudas de morangueiro fora do solo sob diferentes concentrações de nitrogênio nas matrizes e datas de plantio das mudas na Região Sul do RS. Dissertação. (Mestrado em Agronomia). Pelotas: UFPEL. $107 p$.

CALVETE EO et al. 2007. Produção hidropônica de morangueiro em sistema de Colunas verticais, sob cultivo protegido. Revista Brasileira de Fruticultura 29: 524-529.

CALVETE EO et al. 2012. Cultivo de morangueiro em ambiente protegido. In: CHAVARRIA G \& SANTOS HP. Fruticultura em Ambiente Protegido. Brasília: Embrapa. p.149-206.

CHAVARRIA G \& SANTOS HP. 2012. Fruticultura em Ambiente Protegido. Brasília: Embrapa. 278p.

COCCO C et al. 2011. Crown size and transplant type on the strawberry yield. Scientia Agricola 68: 489-493.

COELHO FS et al. 2010. Dose de nitrogênio associada à produtividade de batata e índices do estado de nitrogênio na folha. Revista Brasileira de Ciências do Solo 34: 1175-1183.

COSTA RC et al. 2011. Telas de sombreamento na produção de morangueiro em ambiente protegido. Horticultura 
Brasileira 29: 98-102.

DIAS MSC et al. 2014. Cultivares (Morango: tecnologias de produção ambientalmente corretas). Informe Agropecuário 279. Belo Horizonte: EPAMIG. 35: 39-47.

ENGEL VL \& POGGIANI F. 1991. Estudo da concentração de clorofila nas folhas e seu espectro de absorção de luz em função do sombreamento em mudas de quatro espécies florestais nativas. Revista Brasileira de Fisiologia Vegetal 3 : 39-45.

GIMÉNEZ G et al. 2008. Cultivo sem solo do morangueiro. Ciência Rural 38: 273-279.

HARBINSON J \& ROSENQVIST E. 2003. An Introduction to Chlorophyll Fluorescence. In: De Ell JR. \& TOIVONEN PMA (Eds.). Practical Applications of Chlorophyll Fluorescence in Plant Biology. Boston: Springer. p 1-29.

KADER AA. 1991. Quality and its maintenance in relation to posthaverst physiology of strawberry. In: LUBY JJ. DALE A. (Eds.) The strawberry into the 21 st century. Portland: TimberPress. p. 145-152.

$\mathrm{KIM} \mathrm{HH}$ et al. 2004. Green-light supplementation for enhanced lettuce growth under red- and bluelight-emitting diodes. HortScience 39: 1617-1622.

KIRSCHBAUM DS. 1998. Temperature and growth regulator effects on growth and development of strawberry (Fragaria x ananassa Duch.) Dissertação (MestradoemAgronomia) Florida: University of Florida 123p.

LEFSRUD MG et al. 2008. Irradiance from distinct wavelength light-emitting diodes affect secondary metabolites in kale. HortScience 43: 2243-2244.

MACHADO JTM et al. 2016. Production and physicochemical characteristics of strawberry cultivars produced in organic cropping system. Revista Científica 44: 371-377.

MADAIL JCM et al. 2007. Avaliação econômica dos sistemas de produção de morango: convencional, integrado e orgânico. Pelotas: Embrapa Clima Temperado. 4p. (Comunicado Técnico, 181).

MÉNARD C et al. 2006. Developmental and physiological responses of tomato and cucumber to adtional blue light. Acta Horticulturae 711: 291-296.

PIRES RCM et al. 1999. Estimativa da área foliar de morangueiro. Horticultura Brasileira 17: 86-90.

OUZOUNIS T et al. 2015. Spectral effects of LEDs on chlorophyll fluorescence and pigmentation in Phalaenopsis 'Vivien' and 'Purple Star'. Physiologic Plant 154: 314-327.

ROCHA PSG et al. 2010. Diodos emissores de luz e concentrações de BAP na multiplicação in vitro de morangueiro. Ciência Rural 40: 1922-1928.

ROSA HT et al. 2013. Crescimento vegetativo e produtivo de duas cultivares de morango sob épocas de plantio em ambiente subtropical. Revista Ciência Agronômica 44: 604-613.

SAMUOLIENE $\mathrm{G}$ et al. 2010. The effect of red and blue light component on the growth and development of frigo strawberries. Zemdirbyste Agriculture 97: 99-104.

SORATTO RP et al. 2004. Teor de clorofila e produtividade do feijoeiro em razão da adubação nitrogenada. Pesquisa Agropecuária Brasileira 39: 895-901.

TAIZ L \& ZEIGER E. 2013. Fisiologia Vegetal. 5.ed. Porto Alegre: Artmed. 785p.

TELLES FFF et al. 1977. A simple technique for industrial analysis of total chlorophyll. Revista Ceres 24: 338-340.

TONIN J et al. 2015. Adubação de Liberação Lenta na Produção de Mudas de Morangueiro com torrão. In: XX

Seminário Interinstitucional de Ensino Pesquisa e Extensão. Anais..... Cruz Alta: UNICRUZ. p.17.

ZEIST AR et al. 2014. Comparação de métodos de estimativa de área foliar em morangueiro. Pesquisa Agropecuária Gaúcha 20: 33-41. 